\title{
Supersonic Retropropulsion Experimental Results from the NASA Langley Unitary Plan Wind Tunnel
}

\author{
Scott A. Berry ${ }^{1}$, Matthew N. Rhode ${ }^{2}$, Karl T. Edquist ${ }^{3}$, and Charles J. Player ${ }^{4}$ \\ NASA Langley Research Center, Hampton, VA 23681
}

\begin{abstract}
A new supersonic retropropulsion experimental effort, intended to provide code validation data, was recently completed in the Langley Research Center Unitary Plan Wind Tunnel Test Section 2 over the Mach number range from 2.4 to 4.6. The experimental model was designed using insights gained from pre-test computations, which were instrumental for sizing and refining the model to minimize tunnel wall interference and internal flow separation concerns. A 5-in diameter 70 -deg sphere-cone forebody with a roughly 10 -in long cylindrical aftbody was the baseline configuration selected for this study. The forebody was designed to accommodate up to four 4:1 area ratio supersonic nozzles. Primary measurements for this model were a large number of surface pressures on the forebody and aftbody. Supplemental data included high-speed Schlieren video and internal pressures and temperatures. The run matrix was developed to allow for the quantification of various sources of experimental uncertainty, such as random errors due to run-to-run variations and bias errors due to flow field or model misalignments. Preliminary results and observations from the test are presented, while detailed data and uncertainty analyses are ongoing.
\end{abstract}

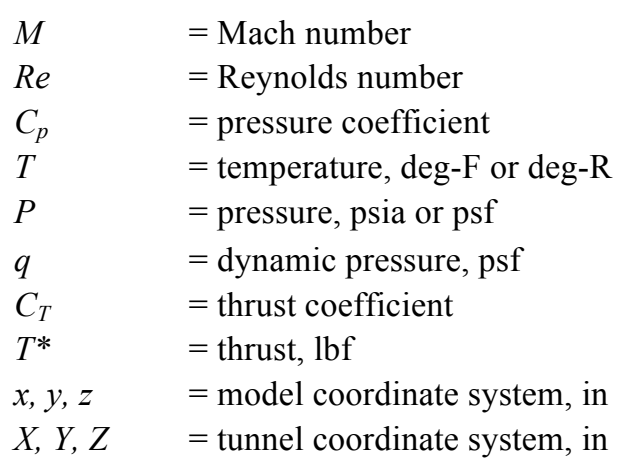

\section{Nomenclature}

$\begin{array}{ll}\alpha & =\text { angle of attack, deg } \\ \beta & =\text { angle of yaw, deg } \\ A_{\text {Ref }} & =\text { area reference, } \mathrm{in}^{2} \\ \phi & =\text { model roll, deg } \\ r, \theta & =\text { model polar corrdinates } \\ \text { Subscripts: } & \\ T & =\text { stagnation or total conditions } \\ \infty & =\text { freestream conditions } \\ j & =\text { jet conditions }\end{array}$

\section{Introduction}

Wtry, descent, and landing (EDL) is a critical component of all planetary surface-exploration programs, essential

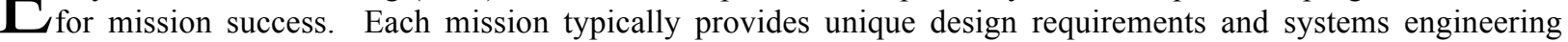
challenges that should be addressed many years ahead of EDL architecture development. Thus, for successful application to future missions, EDL technologies require continuous investment by those interested in space exploration. Although, the many recent successful Mars robotic landings might lead one to infer that EDL is a mature technology. Indeed, with EDL system architectures derived from the Viking-era development effort, all with a 70-deg sphere-cone aeroshell, an ablative thermal protection system, and supersonic parachutes, these missions were blessed with similar design requirements. However, with payload size and weight growing with each successive mission, the limits of the Viking-era approach to EDL is presently being tested. ${ }^{1}$ In particular, these robotic Mars missions have utilized parachutes for a significant portion of the terminal deceleration required to

\footnotetext{
${ }^{1}$ Aerospace Engineer, Aerothermodynamics Branch, m/s 408a, AIAA Associate Fellow.

${ }^{2}$ Aerospace Engineer, Aerothermodynamics Branch, m/s 408a, AIAA Senior Member.

${ }^{3}$ Aerospace Engineer, Atmospheric Flight \& Entry Systems Branch, MS 489, AIAA Senior Member.

${ }^{4}$ Aerospace Engineer, Atmospheric Flight \& Entry Systems Branch, MS 489.
} 
safely land less than a metric ton on the surface. This approach cannot be scaled up to larger payloads due to physical limits imposed by parachute size and materials. For a manned mission to Mars, landed masses on the order of tens of metric tons are required. A proposed alternate to parachutes is to use propulsive deceleration early in the trajectory, even during supersonic flight (instead of just at the terminal-landing phase). Thus, supersonic retropropulsion (SRP), or the use of engine thrust directed into the oncoming supersonic freestream flow, is deemed an enabling technology for future large payload missions to Mars. SRP is currently one of the focus areas of the EDL project in the Exploration Technology Development and Demonstration program. For further discussions of SRP from a systems analysis and performance perspective, see Refs. 2 - 5. A broader SRP-related literature survey is provided in Ref. 6 .

To date, only a handful of studies have been conducted with the aim of further understanding the fluid dynamic phenomena associated with SRP and most of those were performed decades ago, for example see Ref. 7.

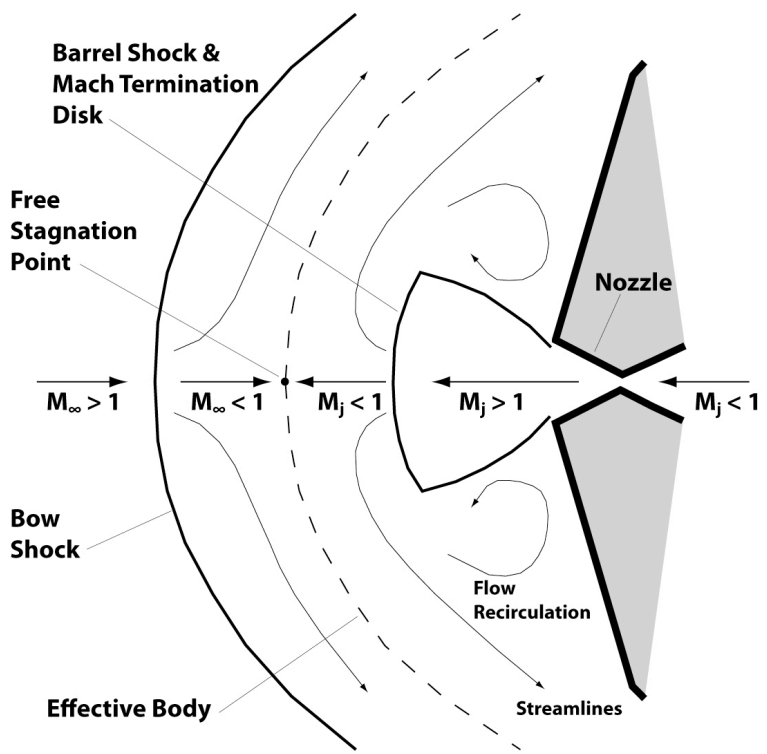

Figure 1 - Conceptual sketch of SRP flow features Typically, these older studies were exploratory in nature, designed to investigate the aerodynamic behavior of various Viking-era configurations. While useful for providing key insights into the complex interaction between a supersonic freestream and an opposing rocket plume, shown notionally in Fig. 1 for a single nozzle, the historical reports do not contain enough detail for comparison against modern computational fluid dynamics (CFD) codes. ${ }^{8}$ For instance, while static force and moment response characteristics are often reported, the interaction dynamics are not discussed, nor captured in the still images and time averaged data. A modern SRP experiment, specifically designed for CFD validation ${ }^{9}$, is intended to allow for higher fidelity comparisons. From a computational perspective, SRP represents a challenging problem for use as a test case for assessing CFD modeling strengths and weaknesses.

The present paper discusses trends and observations obtained from a recent experimental SRP study in the Langley Research Center (LaRC) Unitary Plan Wind Tunnel (UPWT). Reference 10 reviewed the philosophy and approach utilized to design the model and run matrix. From the onset, this study was intended as a validation experiment in support of improved CFD models and capabilities. As a result, both experimentalists and computationalists were heavily engaged in all aspects of the wind tunnel model design and execution of the experiment. For instance, pre-test CFD solutions were instrumental in sizing the model within the tunnel test core to minimize wall interference effects. CFD also highlighted concerns over potential liquefaction within the SRP nozzles, which then led to mitigations alleviating the need for multi-phase-flow computations. On the experimental side, novel approaches for a highly instrumented model design with fast response pressure gages and high-speed digital camera systems were selected to permit monitoring of high frequency unsteadiness (due to the complex fluid dynamics initiated by SRP). Tunnel hardware motion was simulated prior to the test to better understand the bounds of model movement within the facility. These simulations allowed the development of a run matrix dedicated to assessing various sources of measurement uncertainty, such as flowfield non-uniformity and gage-to-gage repeatability. These aspects were discussed in Ref 10. Subsequent sections will provide a quick review of the test and preliminary observations relevant to the SRP experimental data. While this paper is focused strictly on experimental results, separate papers ${ }^{11-13}$ will provide post-test computations with comparisons to data.

\section{Experimental Method}

\section{A. Test Facility}

The NASA LaRC UPWT is a closed-circuit continuous flow pressure tunnel with two test sections that are nominally 7 feet long and 4-ft by 4 -ft in cross section. The test complex building is shown in Fig. 2, while a general layout of the complex is illustrated in Fig. 3. The primary elements of the UPWT are a 100,000-horsepower compressor-drive system, a dry air supply and evacuating system, a cooling system, and interconnecting tubes that allow air circulation through either of the two test sections. The Mach number ranges from approximately 1.50 to 2.86 in Test Section 1 and from 2.30 to 4.63 in Test Section 2. Stagnation pressure can be varied up to a maximum 


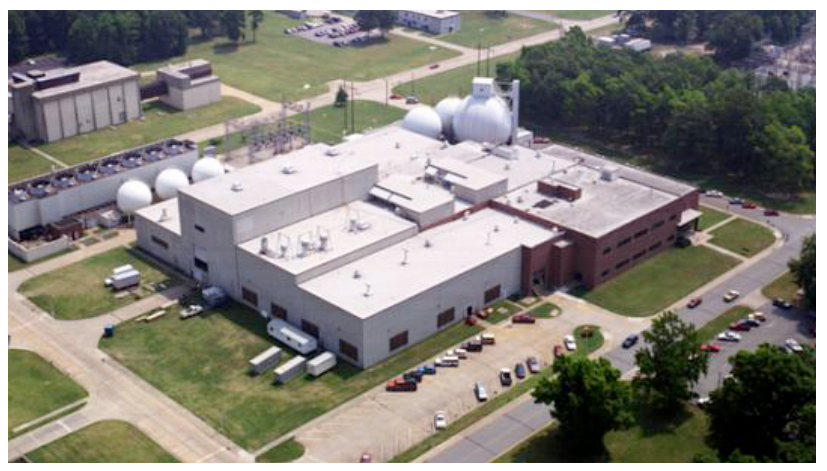

Figure 2 - The Unitary Plan Wind Tunnel complex in Building 1251 at NASA Langley Research Center

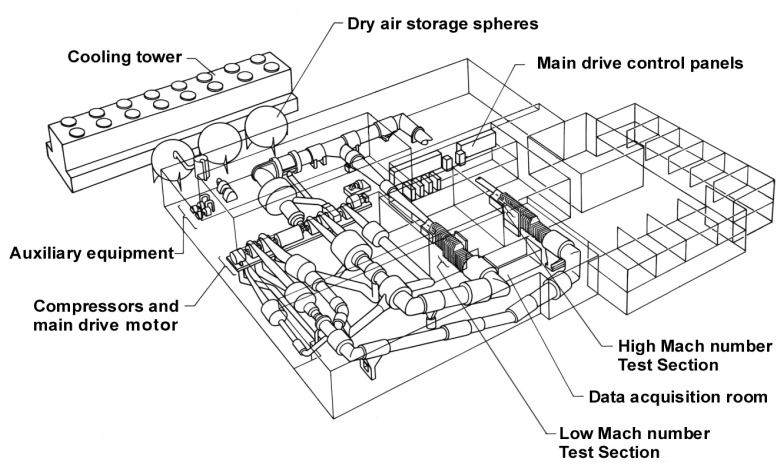

Figure 3 - Schematic of the NASA LaRC Unitary Plan Wind Tunnel complex

of 50 psia in Test Section 1 and 100 psia in Test Section 2. Each tunnel leg has an asymmetric sliding-block type nozzle that accelerates flow to supersonic conditions at the test section. By moving the lower sliding block, the nozzle area ratio is varied to allow alteration of Mach number. Figure 4 provides a sketch of the sliding-block nozzle concept, while Test Section 2 model support system is shown in Fig. 5. The second minimum area downstream of the test section is controlled by hinged sidewalls that provide the required constriction for stabilizing the post-test-section normal shock at each Mach number. More details about the facility, including calibration data, are provided in Ref. 14, while Ref. 15 provides details for planning a test within the UPWT.

Test Section 2 was used exclusively for this study and thus all subsequent facility discussion will focus on the capabilities of this higher Mach number leg. The facility has six centrifugal compressors that are utilized in specific combinations, or modes, depending on the Mach number. For each mode, or Mach number range, the operating envelope upper limit is established by drive system power and stagnation pressure, while the lower limit is dictated by supersonic-flow stability characteristics at reduced pressure. Typical unit Reynolds numbers in UPWT Test Section 2 are 1 to 5 million per foot. To allow for the widest range of SRP nozzle thrust coefficients $\left(\mathrm{C}_{\mathrm{T}}=\mathrm{T} / \mathrm{q}_{\infty} \mathrm{A}_{\text {ref }}\right.$, where $T$ is the total thrust, $\mathrm{q}_{\infty}$ is freestream

Table 1. Nominal UPWT test section 2 flow conditions

\begin{tabular}{cccccc}
\hline \hline $\mathrm{M}_{\infty}$ & $\begin{array}{c}\mathrm{Re}_{\infty} \\
(1 / \mathrm{ft})\end{array}$ & $\begin{array}{c}\mathrm{T}_{\mathrm{T} \infty} \\
(\mathrm{deg}-\mathrm{R})\end{array}$ & $\begin{array}{c}\mathrm{P}_{\mathrm{T} \infty} \\
(\mathrm{psf})\end{array}$ & $\begin{array}{c}\mathrm{P}_{\infty} \\
(\mathrm{psf})\end{array}$ & $\begin{array}{c}\mathrm{q}_{\infty} \\
(\mathrm{psf})\end{array}$ \\
\hline 2.4 & $1.0 \mathrm{E}+06$ & 610 & 814.9 & 55.7 & 224.7 \\
3.5 & $1.0 \mathrm{E}+06$ & 610 & 1485.8 & 19.5 & 167.0 \\
4.6 & $1.5 \mathrm{E}+06$ & 610 & 3922.1 & 12.0 & 177.3 \\
\hline \hline
\end{tabular}
dynamic pressure, and $\mathrm{A}_{\mathrm{ref}}$ is a reference area), only the lowest Reynolds numbers were considered for the present study. The tunnel stagnation temperatures are typically 125 or $150^{\circ} \mathrm{F}$ depending on the mode of operation. Nominal tunnel flow conditions for the range of Mach numbers utilized for this test are provided in Table 1.

Standard Test Section 2 model mounting hardware was utilized for this test, as shown in Figure 5. The basic mechanism is a horizontal wall-mounted strut capable of forward and aft travel (in the X-direction) of 36.25 in. Attached to this strut is a sting support which allows left/right traversal (in the Y-direction) of \pm 20 in. and sideslip

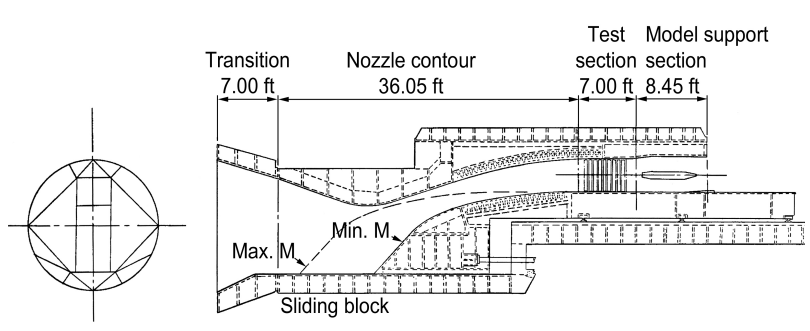

Figure 4 - Schematic of the UPWT Test Section 2 nozzle block



Figure 5 - Test section 2 model support system and coordinate system

3

American Institute of Aeronautics and Astronautics 
angle $(\beta)$ of up to \pm 14 -deg. Forward of the sting support are the angle-of-attack $(\alpha)$ and roll mechanisms, which for this study provided pitch angles from -8 to 20 -deg and roll angles from 0 to 180 deg. The large tunnel size and mounting hardware for the UPWT were ideal for acquiring uncertainty estimation data, as random and bias uncertainties can be assessed by moving and rolling the model to provide sensor-to-sensor repeatability and measurements of flow-field nonuniformity.

An upgraded capability for supplying highpressure air to models has recently been completed at the UPWT. High-pressure air is supplied from a 5000 psia bottle field and regulated via a digital control valve (DCV). The DCV provides control of temperature, (using an inline heater), pressure, and mass flow rate to user-specified values and tolerances.

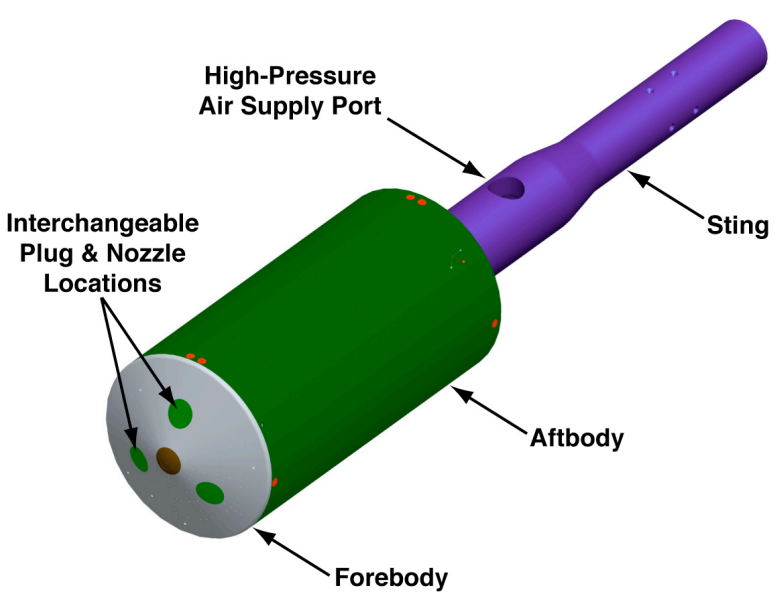

Figure 6 - Oblique view of UPWT SRP model assembly The DCV provides control of temperature from ambient to $275^{\circ} \mathrm{F}$ and pressure from 50 to $3800 \mathrm{psia}$. The mass flow control range is 0.02 to $30 \mathrm{lb} / \mathrm{sec}$ at these conditions. Control accuracy is better than $\pm 2 \%$ for the pressure range of $50-250 \mathrm{psia}, \pm 1 \%$ for the pressure range of $250-3800$ psia, and $\pm 5^{\circ} \mathrm{F}$ in temperature.

\section{B. Model}

Reference 10 provides details of model design effort. An oblique view of the final design in Fig. 6 shows a 5-in diameter SRP model comprised of a highly instrumented 70-deg sphere-cone forebody with locations for 4 nozzle or plug inserts followed by a cylindrical aftbody. The assembled model was designed with a partially hollow sting, as shown in cutaway sketch of Fig. 7, that feeds an internal plenum connected to each nozzle location via a fourfingered manifold. Note that the plenum is a constant diameter pipe with a 5-deg flare leading to the manifold. The predicted Mach number within the final plenum design is approximately 0.1 at worst-case conditions. The sting/plenum/manifold assembly provides the structural load path to hold the forebody with either plugs or nozzles in place. The 9.55-in long aftbody, comprised of two thin-walled half cylinders, provides an enclosure to protect internal instrumentation (also shown in Fig. 7) and carries no load. Nozzle locations include one on model centerline and three on the forebody half-radius spaced $120^{\circ}$ apart. The insert locations can host either 4:1 exit-tothroat area ratio nozzles or plugs that fit flush to the forebody, providing the baseline configuration. Configuration changes are handled by removing one side panel and sliding the forebody forward (without disconnecting the ports) to replace the inserts.

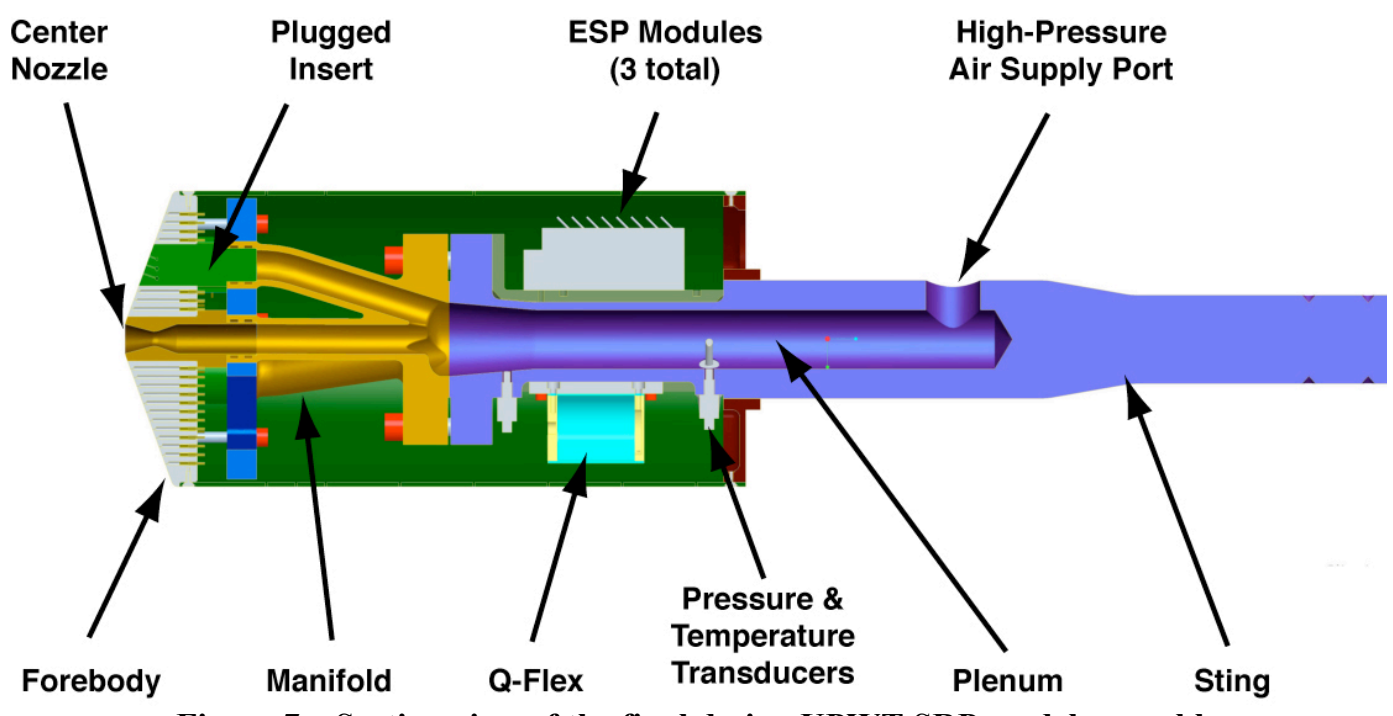

Figure 7 - Section view of the final design UPWT SRP model assembly

4

American Institute of Aeronautics and Astronautics 


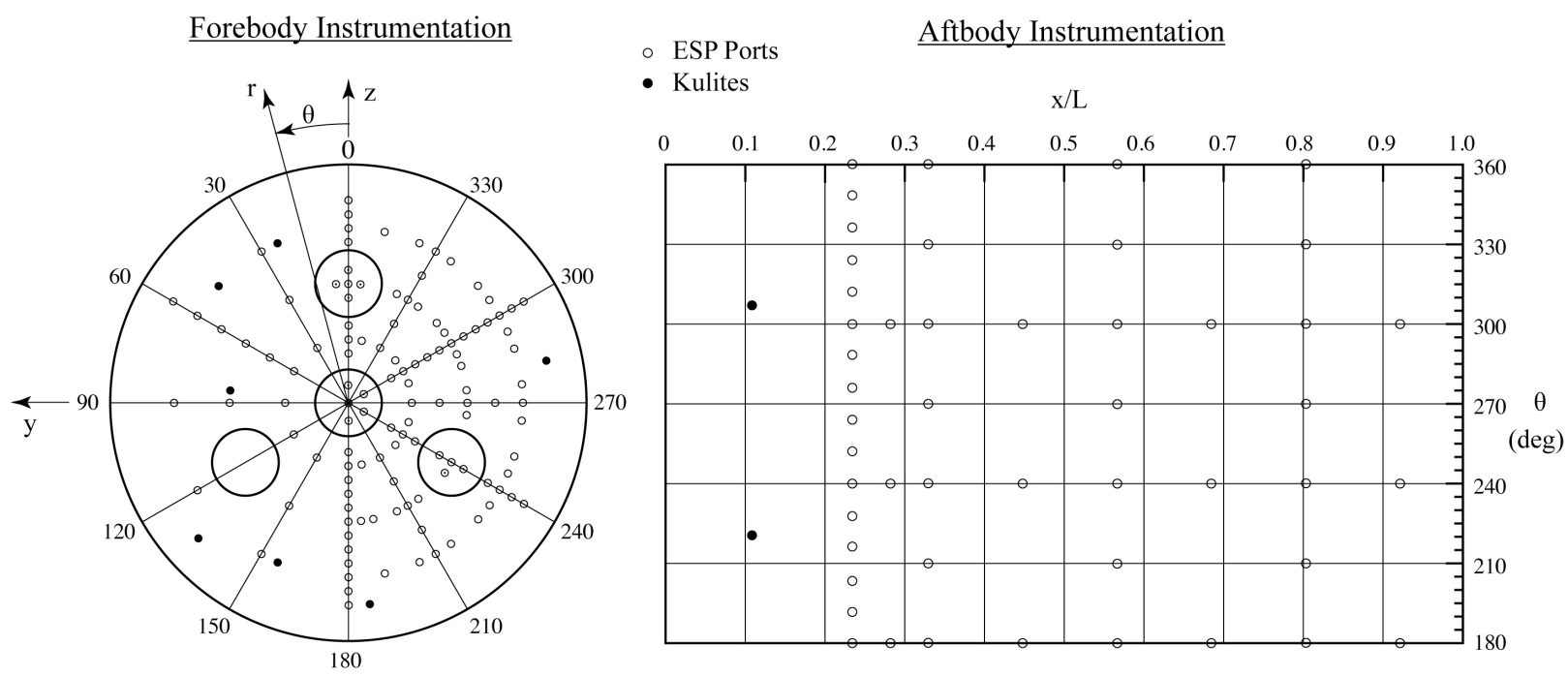

Figure 8 - Surface instrumentation layout and model coordinate system

\section{Instrumentation}

Experimental measurements were acquired at 167 surface pressure ports connected via 0.040 -inch-diameter flexible urethane tubing to three Pressure Systems Inc. (PSI) electronically scanned pressure (ESP) transducer modules located inside the model. Two 64-channel modules $(0-5 \pm 0.005$ psid $)$ were used to measure 118 forebody ports and 4 aftbody ports. A 48-channel $(0-2.5 \pm 0.003$ psid $)$ module was used to measure pressures at the remaining 45 ports. The surface instrumentation layout is shown in Figure 8. All three modules were teed to a hard vacuum to provide absolute pressure measurements. Three separate reference pressures were supplied by Ruska Model 6211-801 pressure gages $(0-38 \pm 0.004 \mathrm{psia})$ to transducers on each ESP module and were monitored to check for drift in the pressure measurements. In-situ ESP calibrations were performed using the system Model 8432-15A pressure calibration unit (PCU, 0-15 \pm 0.003 psia) when drift exceeded 0.0175 psi.

Seven 0.0625 -inch-diameter Kulite XCS-062-5A pressure transducers $(0-5 \pm 0.013$ psia) were mounted flush to the model forebody surface with adhesive potting material and used to measure fluctuating surface pressures. The locations of the Kulites are shown in Fig. 8. Two additional Kulite transducers were mounted in the model aft shell but were damaged during model assembly. Output signals from the Kulite gages were split to both standard and high-speed data acquisition systems to provide simultaneous time-averaged and unsteady pressure measurements.

Pressures were measured inside the model at different locations along the high-pressure airflow path using up to four Kulite XT-190-2000A pressure transducers $(0-2000 \pm 2 \mathrm{psia})$. Two transducers were located at different stations in the model plenum, with the gages mounted flush to the plenum inner surface. The remaining pressure transducers were connected to interior surface ports located 0.417 inches upstream of the nozzle inlets for the center nozzle and one of the half-radius nozzles. Figure 9 shows the center nozzle with pressure and temperature instrumentation. These transducers were active only when their respective nozzles were installed in the model. Plenum-flow temperatures were measured using a 0.236 -in diameter Omega RTD-NPT-72-A platinum resistance temperature detector (RTD) probe (132-910 $\pm 1 \mathrm{R}$ ) located 0.5 inches into the high-pressure airflow (see Fig. 7). Additionally, each of the two instrumented nozzles contained a Type $\mathrm{K}$ thermocouple $(132-2742 \pm 4 \mathrm{R})$ mounted flush to the inside surface and opposite of the plenum pressure port.

A NASA Langley-built Q-Flex accelerometer was mounted inside the model and used to directly measure model pitch angle during the test. The device was calibrated in place as a function of pitch and roll angles using a multi-axis Langley



Figure 9 - Close up of the instrumented center nozzle 
Angle Measurement System (AMS) installed on the model during setup. The resultant angular calibration accuracy was approximately \pm 0.01 degrees.

Eight Type $\mathrm{J}$ thermocouples $(492-1842 \pm 4 \mathrm{R})$ were installed to monitor the thermal environment inside the model during the test. A thermocouple was mounted underneath each ESP module and accelerometer, while the remaining four thermocouples were mounted inside the aft shell at approximately half the model length and every 90 degrees around its circumference.

A calibrated Flow-Dyne Engineering subsonic venturi flow meter with 1.503-inch-diameter inlet and 0.695-inchdiameter throat was installed in the high-pressure air line just outside the test section and used to measure nozzle mass flow rate. The venturi inlet pressure was measured using a Druck PDCR 4060 pressure transducer $(0-3000 \pm$ $2.4 \mathrm{psia}$ ), while the inlet temperature was measured using a 0.25 -inch-diameter Type $\mathrm{T}$ shielded thermocouple probe $(132-1122 \pm 2 \mathrm{R})$. Pressure drop across the venturi throat was measured with a Bell \& Howell Model 4-351-0004 differential pressure transducer $(0-100 \pm 0.05$ psid). Mass flow rate uncertainty is estimated to be approximately $0.07 \mathrm{lbm} / \mathrm{sec}$.

To capture flow field dynamics between bow and barrel shocks, a high-speed digital camera was utilized to record Schlieren video. The Phantom 12, from Vision Research, is a 1-megapixel camera capable of taking more than 6200 frames per second (fps) at full $1280 \times 800$ resolution and up to 1,000,000 fps at reduced resolution. For the present test, framing rates between 5,000 and 10,000 fps were utilized.

\section{Data Acquisition \& Reduction}

Model surface pressures measured with the ESP modules were acquired with the PSI 8400 System at $10 \mathrm{~Hz}$. The remaining data channels were acquired at $30 \mathrm{~Hz}$ through a NEFF 620 signal conditioner/multiplexer system. Both systems used a sampling period of 2.5 seconds. All channels were processed through analog 1-Hz, low-pass, 4-pole Butterworth filters and recorded using a MODCOMP 88100 computer with 16-bit analog-to-digital (A/D) conversion. Unsteady pressure data from the Kulite transducers were sampled at 40,000 $\mathrm{Hz}$ for a 2.5 -second sampling period using a National Instruments/Labview-based high-speed data system synchronized to the standard data system. These data were processed through a $20 \mathrm{kHz}$ low-pass filter and recorded with 16-bit A/D conversion.

Raw voltages from the instrumentation were recorded and processed in real time (through respective calibration functions) into engineering unit values for real-time display, monitoring, and plotting. Facility flow conditions were calculated via standard gas dynamic equations using measured tunnel stagnation conditions and calibrated values of freestream Mach number. These flow conditions were then used to compute surface pressure coefficients, nozzle pressure ratios, nozzle exit-to-static pressure ratios, and nozzle thrust coefficients.

The measured plenum static pressures were corrected to total pressure values using total-to-static pressure ratios calculated from estimates of the plenum Mach number. These estimates were computed from a binomial approximation of the mass flow rate equation using the measured mass flow rates, plenum temperatures, and plenum cross section areas, and are valid for small Mach numbers. Model plenum and nozzle exit conditions were calculated using GASPROPS ${ }^{16}$ to account for real-gas effects, the latter being based on plenum total conditions and nozzle area ratios. The thrust of each nozzle was computed from total measured mass flow rate and the ratio of individual nozzle throat area to total nozzle throat area.

The model position was computed relative to the test section coordinate system for each set point based on axial and lateral model support system positions and pitch and yaw angles.

After completion of the test, Schlieren video data was converted from Vision Research (CINE) to AVI format, including an overlay of test parameters for sharing with the broader community. Further video processing was done using a free program called ImageJ from National Institute of Health. ${ }^{17}$ Pressure data was compared using software written in the Data Engineering Scripting Language (DESL). ${ }^{18}$ The high frequency data was analyzed using MATLAB. ${ }^{19}$

\section{E. Run Matrix \& Test Procedures}

The run matrix is summarized in Table 2, in which the sequencing of parametric variation is ordered from difficult to easy. The first step in the test was model assembly and leak checking (the configuration of interest). Then, the tunnel was secured and the proper flow conditions established. If nozzles were installed, the next step was to set the desired thrust coefficient (by setting the desired plenum pressure and temperature). Then, the model was positioned at the proper location and orientation to begin the programmed angle of attack sweep. All desired roll angles were acquired before moving to the next position. Once all desired locations were acquired, nozzle thrust was adjusted as appropriate for the next case in the run matrix. Finally, the tunnel flow conditions were adjusted as 
required. This sequence of events was repeated until all runs in matrix were obtained, after which the tunnel was halted and opened to make the next configuration change.

The model allows for four basic configurations, as listed in Table 2: (1) baseline, with all four nozzle inserts plugged; (2) center nozzle, with three peripheral locations plugged; (3) trinozzle, with only the center plugged; and (4) quad-nozzle, with no plugs. During pre-test planning, the first three configurations were deemed a high priority for this test entry, while the quad configuration was considered a lower priority. In the end, all four configurations were tested.

To minimize the number of tunnel conditions while maximizing thrust coefficient, only the lowest attainable Reynolds numbers were considered for the full range of Mach numbers. At Mach of 2.4 and 3.5, $\mathrm{Re}_{\infty} \mathrm{was} 1 \times 10^{6} / \mathrm{ft}$; while for Mach 4.6, $\mathrm{Re}_{\infty}$ was $1.5 \times 10^{6} / \mathrm{ft}$. The tunnel operating envelope did not allow testing at $\mathrm{M}_{\infty}=4.6$ and $\mathrm{Re}_{\infty}=$ $1 \times 10^{6} / \mathrm{ft}$. The Mach number sweep was considered a high priority for this test entry.

When nozzles were installed, the plenum pressure was controlled and adjusted via the DCV, with a fixed temperature near 170-degF, to provide the desired thrust coefficients listed in Table 2. Considering the intent of this study, a full range of thrust coefficients was considered a high priority. Initially, the goal was to acquire a wider range of thrust coefficients (up to 10), but tunnel blockage effects limited the scope of this entry. In some cases, other thrust cases than listed in Table 2 were acquired.

A full range of streamwise (X) and lateral (Y) model translations were considered important for uncertainty estimation, especially for the baseline configuration, to provide repeatability data from different stations within the tunnel. For the baseline configuration, independent translations in either X or Y were considered a high priority, while combined translations in both $\mathrm{X}$ and $\mathrm{Y}$ were considered important only if time permitted. For the nozzle configurations, only $\mathrm{X}$ translations were considered if time permitted, while combined $\mathrm{X}$ and $\mathrm{Y}$ translations were lowest priority. Notional model translation locations are listed in Table 2.

To provide greater spatial coverage with the clustered instrumentation, the model was rolled to set angles of 0 , 60,120 , and 180-deg. The model rolls were intended to provide repeatability data in combination with angle of attack cases (i.e. $\alpha=-4$-deg with 0 -deg roll is a repeat of $\alpha=4$-deg with 180 -deg roll) to help establish flow-field non-uniformity uncertainties.

For the $\alpha$-sweep, the tunnel angle of attack mechanism was programmed to pause at $0, \pm 4, \pm 8,12,16$, and 20 deg. The typical sweep sequence included nine pause points, starting at -8-deg and proceeding to 20-deg, followed by 0 -deg repeat. There were a few cases, at higher angles of attack and thrust coefficients, in which the tunnel showed signs of nearing tunnel unstart, so these cases were avoided.

Figure 10 provides a photo of the internal volume of the model (with one half of the afbody removed) showing the pressure tubing, quick disconnects, and thermocouple wires. Figure 11 provides an installation photo of the tri-
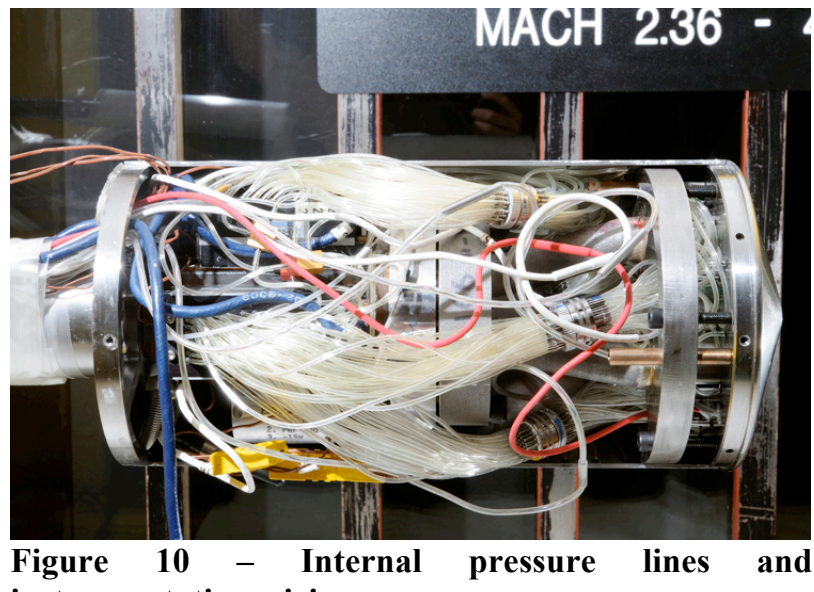
instrumentation wiring



and Figure 11 - Tri-nozzle model and typical location of external high-pressure $\&$ instrumentation lines

7

American Institute of Aeronautics and Astronautics 
nozzle configuration, which shows the tunnel hardware, high-pressure-air line, and instrumentation wiring bundles. Note that all connections to the model required extra slack to allow a full range of motion without binding. Before installation into the tunnel, a pressure qualification test of the model was performed to $3750 \mathrm{psia}$, which allowed for safe operating pressures up to $2500 \mathrm{psia}$. The tunnel, however, had relief valves for their high-pressure system set to 2350 psia.

\section{Discussion of Results}

The test began in the LaRC UPWT on July $1^{\text {st }}$, 2010. All high priority objectives were accomplished with the exception of late test repeat runs on the tri-nozzle configuration. There were also a couple of mid-level priority objectives achieved.



a) Mach 2.4

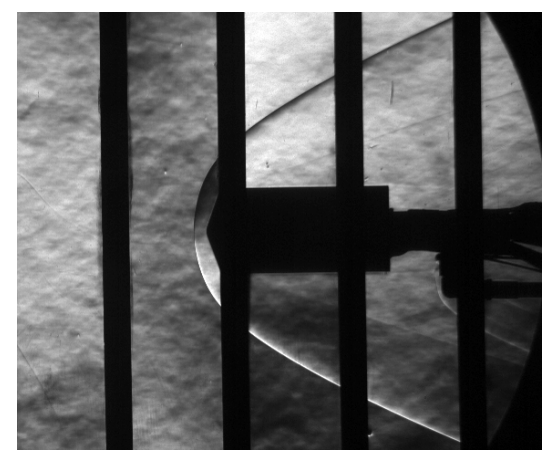

b) Mach 3.5

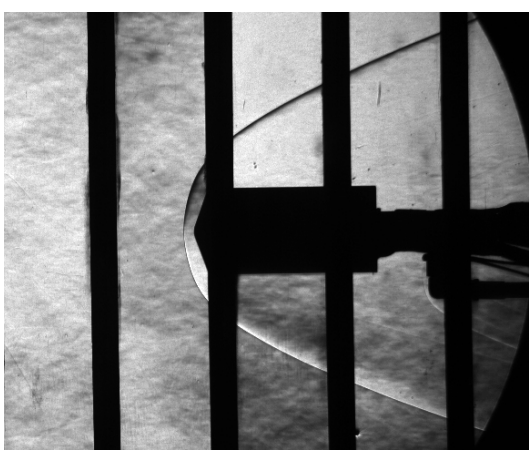

c) Mach 4.6

Figure 12. Effect of Mach number for the baseline configuration at $a=0$-deg

\section{A. Baseline Configuration}

Baseline configuration runs were acquired mainly to allow quantification of various sources of experimental uncertainty, including both random and bias errors. The baseline configuration was preferable for the uncertainty assessment, as it removes any possible influence of unsteady flow effects that could alter or mask the individual uncertainty components. For investigating random errors, repeat runs were acquired with the model in exactly the same location and orientation at various times during the test, to extract random uncertainty for this experiment. Lateral and streamwise translations, coupled with the model roll angles, allow for sensor-to-senor comparisons such that instrumentation and flow-field non-uniformity uncertainties can also be estimated. Model translations in the axial direction were 15-in forward and 10-in back from the center-point position. In the lateral direction, the model translations were \pm 8 -in. For the baseline configuration, all four roll-angle positions were acquired. The uncertainty assessment task is ongoing and will be presented separately in a forthcoming paper.

Figure 12 shows Schlieren images for the baseline configuration at $\alpha=0$-deg over the range of Mach numbers tested. These images illustrate the effect of Mach number on the bow shock, indicating a smaller bow shock standoff distance and steeper shock angle with increasing Mach. Note that the distance between the slats in the Schlieren window is 5.5-in, with each slat measuring 1.25-in. These values can be used to estimate bow shock location as a function of Mach number, with the standoff distance decreasing by a factor of approximately two when going from Mach 2.4 to 4.6.

The corresponding comparison of measured surface pressures along one symmetry plane as compared against pre-test CFD results ${ }^{8}$ is shown in Figure 13. Similar comparisons were used realtime during the early portion of the test to provide a quick-look assessment of data quality. The asrun conditions for these cases closely matched



Figure 13 - Plot of the baseline configuration pressure data showing the effect of Mach number for $\alpha=0$-deg

8

American Institute of Aeronautics and Astronautics 
those used for pre-test computations. The agreement between experiment and computation for the baseline configuration provided confidence that surface instrumentation was behaving as expected. Note that a few sensors located on the plug inserts yielded erroneous results, possibly due to a pinching of the pressure tubes, and those experimental data were omitted. The pressure coefficient increases by roughly $5 \%$ between Mach 2.4 and 3.5, but less than $1 \%$ going to Mach 4.6. The plateau for the two highest Mach numbers is indicative of Mach number independence, as the stagnation point pressure coefficient asymptotes to a value near 1.8 as Mach number increases.

\section{B. Center Nozzle Configuration}

The single nozzle configuration provides the simplest nozzle case for CFD comparisons and is most easily comparable to historical results. Data were acquired for $\mathrm{C}_{\mathrm{T}}$ ranging from roughly 0.25 to 4.0 , with the upper limit being dictated by tunnel blockage and unstart concerns. A few streamwise translation cases were planned but were performed due to time constraints. Many of the 60 and 120-deg roll cases were also dropped, as these were deemed of lower priority.

The effect of increasing thrust coefficient for the center nozzle configuration at $\mathrm{M}_{\infty}=2.4$ and $\alpha=0$-deg is shown in Fig. 14. By comparing Fig. 14a to Fig. 12a, the bow shock standoff distance is seen to increase by roughly $300 \%$ (from 1.12-in to 4.38-in) due to a small amount of retro propulsion. An increase in $\mathrm{C}_{\mathrm{T}}$ from 0.5 to 4.0 resulted in an additional forward movement of the bow shock of nearly 7 -in, or roughly another $250 \%$. As can be seen in these images, the flow emanating from the nozzle forms a classic expansion fan and barrel shock, terminated by a curved Mach disk just behind the bow shock. At the lowest thrust coefficient (Fig. 14a), the Mach disk is roughly half the model diameter. At the highest $\mathrm{C}_{\mathrm{T}}$ (Fig. 14d), the Mach disk is nearly twice the model diameter (although most of the Mach disk is obscured behind a window slat). The overall flow structure appeared steady with the exception of some unsteadiness seen near the triple points to either side of the Mach disk. This observation is made based upon review of the high-speed video and is not reflected in the still images shown. Generally, the center


a) Run 319, $\mathrm{C}_{\mathrm{T}}=\mathbf{0 . 5}$

\section{b) Run 139, $C_{T}=1.0$}


c) Run 141, $C_{T}=2.0$

d) Run 136, $\mathrm{C}_{\mathrm{T}}=4.0$

Figure 14 - Center nozzle Schlieren images for range of $C_{T}$ at $M_{\infty}=2.4$ and $\alpha=0-d e g$

American Institute of Aeronautics and Astronautics 
nozzle provided for a steady flow field for angles of attack below 10-deg across the spectrum of Mach numbers and thrust coefficients. At angles of attack above 10-deg, the bow shock became unsteady in certain cases. Flow unsteadiness as identified by the Schlieren video will be discussed further in a following paragraph.

Figure 15 provides the corresponding surface pressure measurements for the range of center nozzle thrust cases shown by Fig. 14. The nozzle flow greatly reduces forebody $C_{P}$ from slightly above 1.5 (for the baseline cases, shown in Fig. 13) to below zero. Negative pressure coefficients are an indication that there is no forebody drag contribution.

Flow unsteadiness, as captured by the highspeed video shot at $5000 \mathrm{fps}$ or greater, is difficult to represent with a single extracted image. To better illustrate the unsteadiness, video processing was employed. Figures 16 and 17 provide an examination of flow unsteadiness for the center nozzle at Mach 4.6 (Run 165) for both the 0-deg and 12-deg angle of attack cases, respectively. The first image in these figures provides a single frame extracted from the video file, showing specific flow features frozen in time. The second image provides the average intensity of all the frames in the video file. This particular type of processing is representative of Schlieren video taken with standard video framing rates (30 fps), which tends to accentuate only steady features. The unsteady regions show up as a blurring of the average flow structure. The last image provides the standard deviation of all the frames in the video. In this case, regions of unsteadiness are emphasized by bright white regions where flow fluctuations are most intense. Thus for the model at $\alpha=0-\mathrm{deg}$, flow unsteadiness is most notable at the triple points to either side of the Mach disk at the end of the nozzle barrel shock. The bow shock also has a very thin white line, indicating some small-scale fluctuations, most likely due to tunnel turbulence. For the model at $\alpha=12$-deg, the region of flow unsteadiness has grown from the lower triple point to encompass the lower portion of the bow shock.

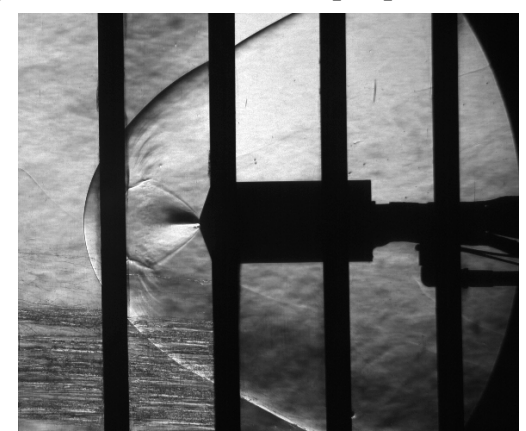

a) Single image from video


b) Average intensity of all frames

c) Standard deviation of all frames

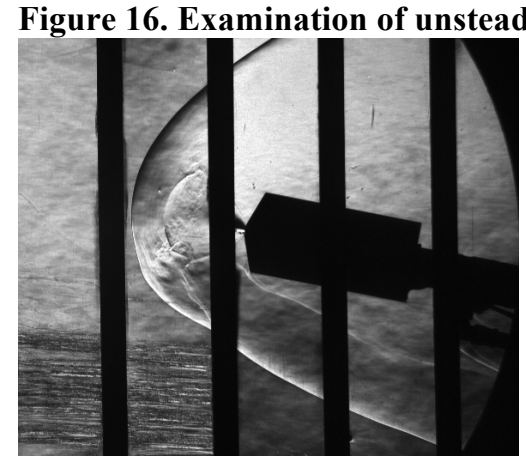

a) Single image from video

4.6 and $\mathrm{a}=0-\mathrm{deg}$ (Run 165)
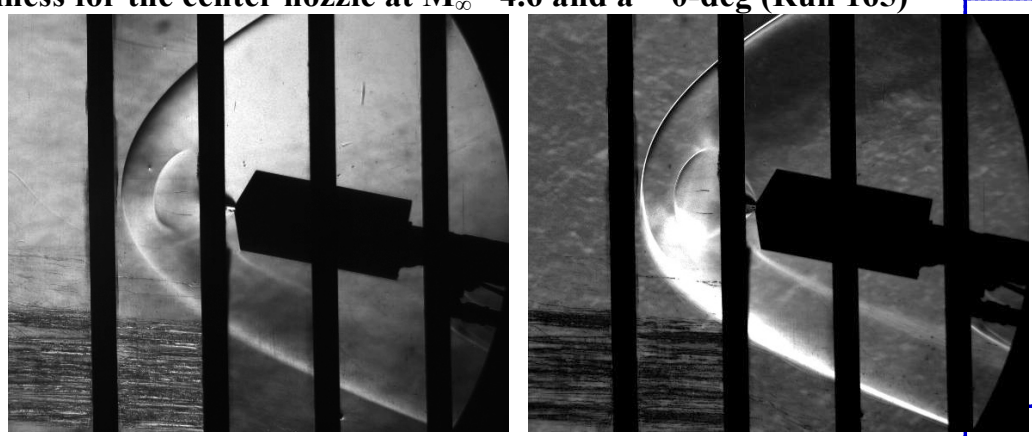

b) Average intensity of all frames

c) Standard deviation of all frames

Figure 17. Examination of unsteadiness for the center nozzle at $M_{\infty}=4.6$ and $a=12-d e g$ (Run 165)

10

American Institute of Aeronautics and Astronautics 
The surface Kulite gages were included to allow assessment of flowfield unsteadiness. Thus far, this data set has not been extensively reviewed, but a few cases have been analyzed. For the $\alpha=0$-deg case discussed above, predominant frequencies from the forebody Kulite measurements range from 1.7 to $2.3 \mathrm{kHz}$ depending on forebody location. The frequency drift is correlated with forebody vertical location, and may be an artifact of flow angularity, which calibration report indicates is one degree upward. ${ }^{14}$ For this case, the model is rolled 180-deg, so the peak frequency is lower towards the windward side and slightly higher to the leeward side.

\section{Tri-Nozzle Configuration}

The tri-nozzle represents another configuration that has been investigated in the past, and is sometimes referred to as a peripheral nozzle configuration. With the nozzles placed outboard away from the centerline of the model, a high-pressure region inboard is expected that may contribute some aerodynamic drag. Most high priority objectives were accomplished with the tri-nozzle configuration with the exception of higher thrust coefficient and late repeat cases. All lower priority objectives, including some model translation cases, were omitted due to time constraints.

Overall, the tri-nozzle configuration produced more flowfield unsteadiness than the center nozzle. Figure 18 provides an examination of the unsteadiness in the Schlieren data for the range of Mach numbers obtained with the tri-nozzle configuration at $\alpha=0$-deg and $\mathrm{C}_{\mathrm{T}}=2.0$. As before, the first column of images provides an extracted frame for each case, while the second and third columns provide the results of image processing with average intensity and standard deviation, respectively. Again, the average intensity images mask the unsteady nature of the flowfield, but as can be seen in the standard deviation images the entire shock system is unsteady for all three Mach
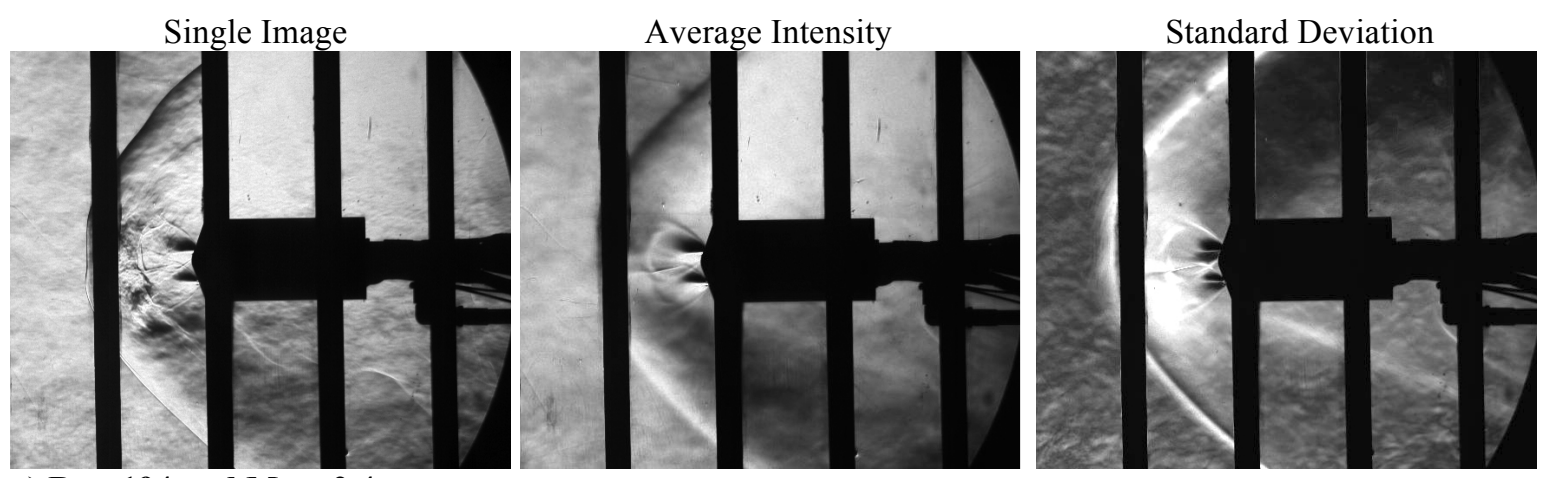

a) Run 194 and $M_{\infty}=2.4$


b) Run 226 and $M_{\infty}=3.5$
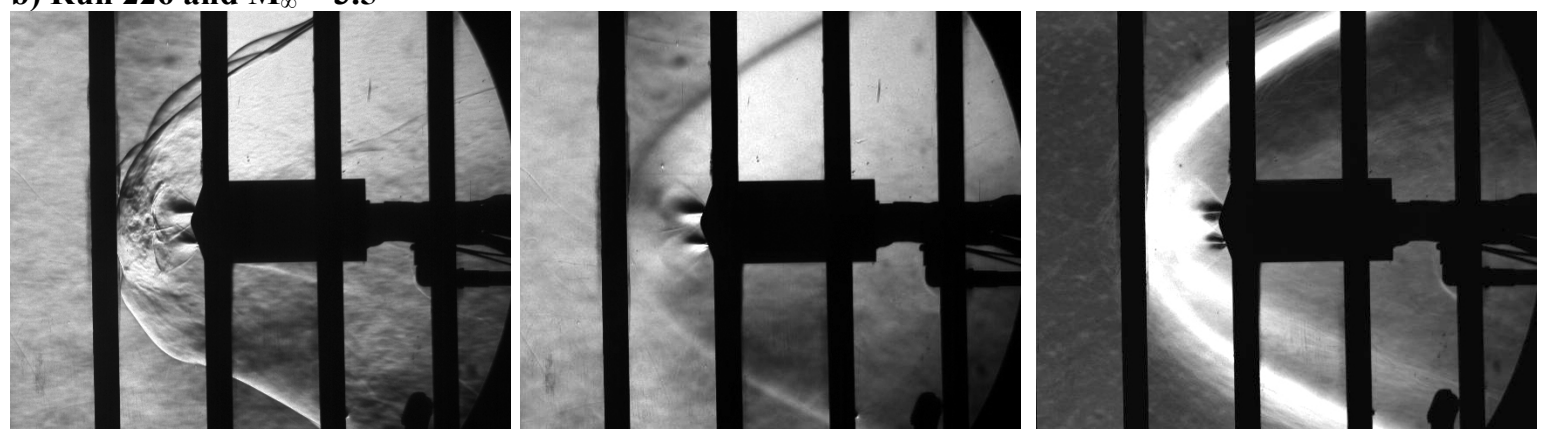

c) Run 248 and $M_{\infty}=4.6$

Figure 18 - Tri-nozzle Schlieren images for range of Mach at $\alpha=0$-deg and $C_{T}=\mathbf{2 . 0}$

11

American Institute of Aeronautics and Astronautics 
numbers. Note that the bow shock is closer to the model than the corresponding center nozzle case (compare Fig 14c to Fig 18a). Having three nozzles fed from a central plenum provides for a lower pressure ratio across the nozzle for the same thrust coefficient and this contributes to a reduction in the standoff distance of the Mach disks and smaller barrel shocks. The interaction of the three jets in close proximity to each other reinforces fluctuations in the region between the jets, which then causes the bow shock to oscillate. The level of unsteadiness increases with increasing Mach number. In addition, for the limited range of thrust coefficient cases that were acquired (not shown), the unsteadiness appeared to increase as thrust was increased. In regards to angle of attack, there were a few of the higher- $\alpha$ cases where the flow structure switched to being quasi-steady with only occasional bursts of unsteadiness. An example of this behavior will be provided in the next section.

The effect of Mach number on $C_{P}$ for the tri-nozzle configuration at $\alpha=0$-deg and $C_{T}=2.0$ is shown in Fig. 19 . As expected the pressure is higher in the region between peripheral nozzles, with the higher Mach number cases having positive $\mathrm{C}_{\mathrm{P}}$ values. In addition, as shown earlier with the baseline configuration, the trend with increasing Mach number is to increase the forebody pressure coefficient.

\section{Quad-Nozzle Configuration}

The quad-nozzle configuration was originally a low priority objective for this test entry, however the team made a real-time decision during the test to acquire this unique and potentially interesting data. Due to time constraints, only two thrust coefficient cases were acquired for the range of Mach and angles of attack.

The quad-nozzle configuration provided a mixture of results, with certain cases being noticeably steadier than the tri-nozzle and others not. Figure 20 provides results of the image processing analysis for the quad configuration at $\mathrm{M}_{\infty}=2.4, \alpha=0-\mathrm{deg}$, and $\mathrm{C}_{\mathrm{T}}=2.0$. For this case the bow shock is quite steady, however one can see unsteady flow structures in the region near the barrel shocks. Figures 21 and 22 provide the effect of angle of attack for these same conditions, but with model roll angles of 0 and 180-deg, respectively. In one case, with one of the peripheral nozzles in the upper quadrant (Fig. 21, $\phi=0$-deg), increasing angle of attack provides for increasing unsteadiness, especially above $\alpha=12 \mathrm{-deg}$. The unsteadiness is most evident by looking at the areas of white in the standard deviation images. In the other case, when the lone nozzle is oriented in the lower quadrant (Fig. 22, $\phi=180$-deg), steady results are obtained for the entire range of angles of attack. While the bow shock remains very steady for these cases, the region in front of the merging barrel shocks does contain some unsteadiness. Perhaps, having only one nozzle angled towards the oncoming flow allows relief of any unsteadiness generated within the interaction zone (between barrel shocks) in such a way that the main bow shock structure is not affected. An interesting observation gleaned from studying these images is that the side of the model with the single peripheral nozzle is the
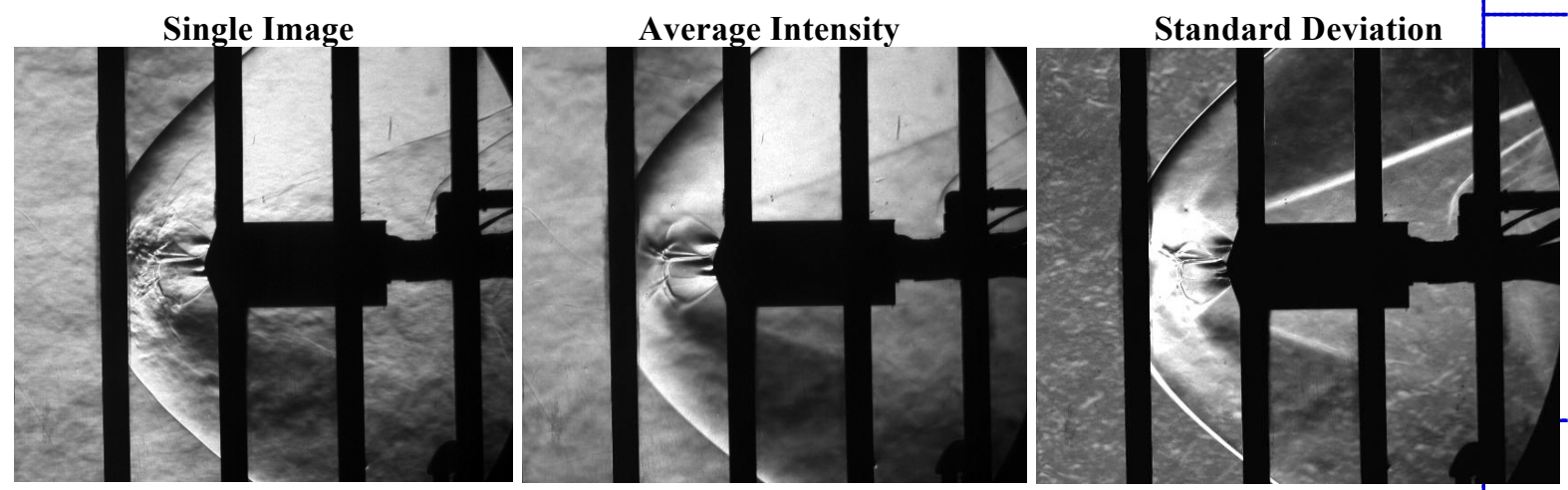

Figure 20 - Quad-nozzle Schlieren images at $M_{\infty}=2.4, \alpha=0-d e g$ and $C_{T}=2.0$ ( Run 288)

12

American Institute of Aeronautics and Astronautics 



e) $\alpha=20$-deg

Figure 21 - Quad-nozzle Schlieren images for range of $\alpha$ at $M_{\infty}=2.4, C_{T}=2.0$, and $\phi=0$-deg (Run 288) 
Single Image

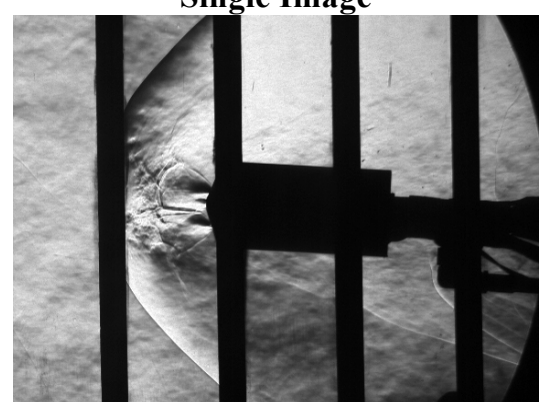

a) $\alpha=4-d e g$

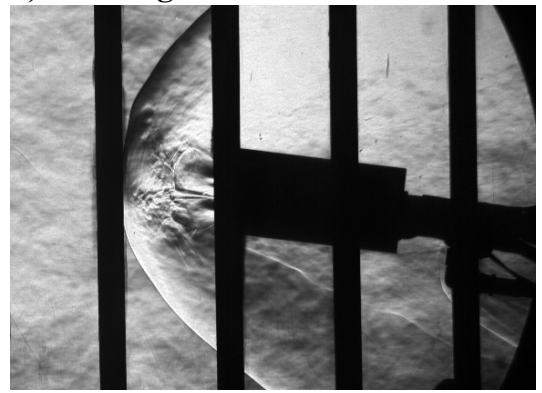

b) $\alpha=8-$ deg

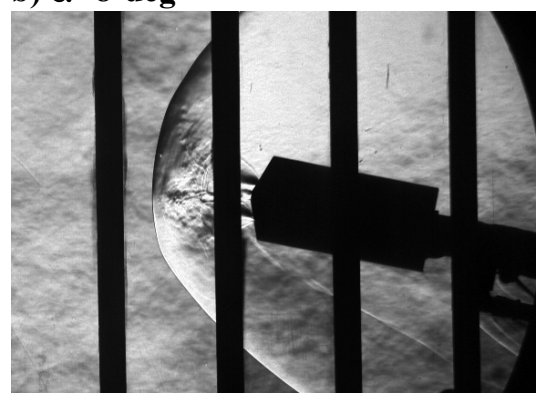

c) $\alpha=12-\mathrm{deg}$

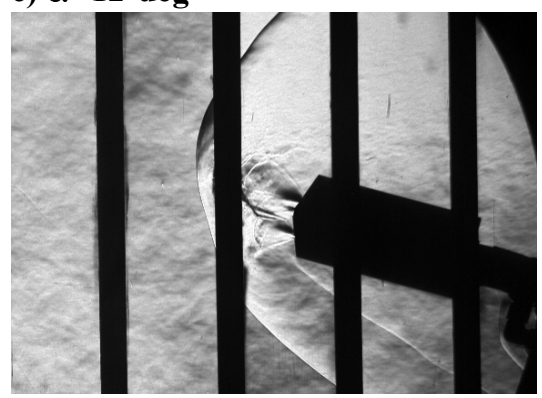

d) $\alpha=16-$ deg

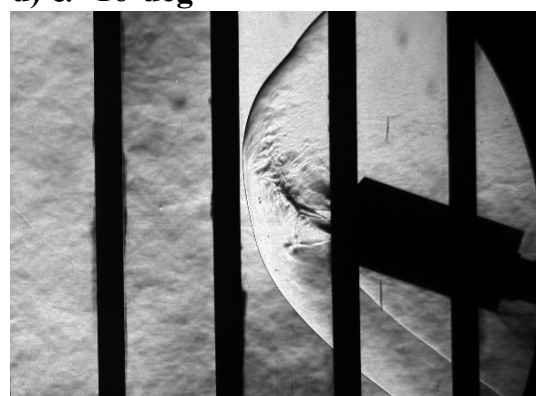

e) $\alpha=20$-deg

Figure 22 - Quad-nozzle Schlieren images for range of $\alpha$ at $M_{\infty}=2.4, C_{T}=2.0$, and $\phi=180-d e g$ (Run 291)
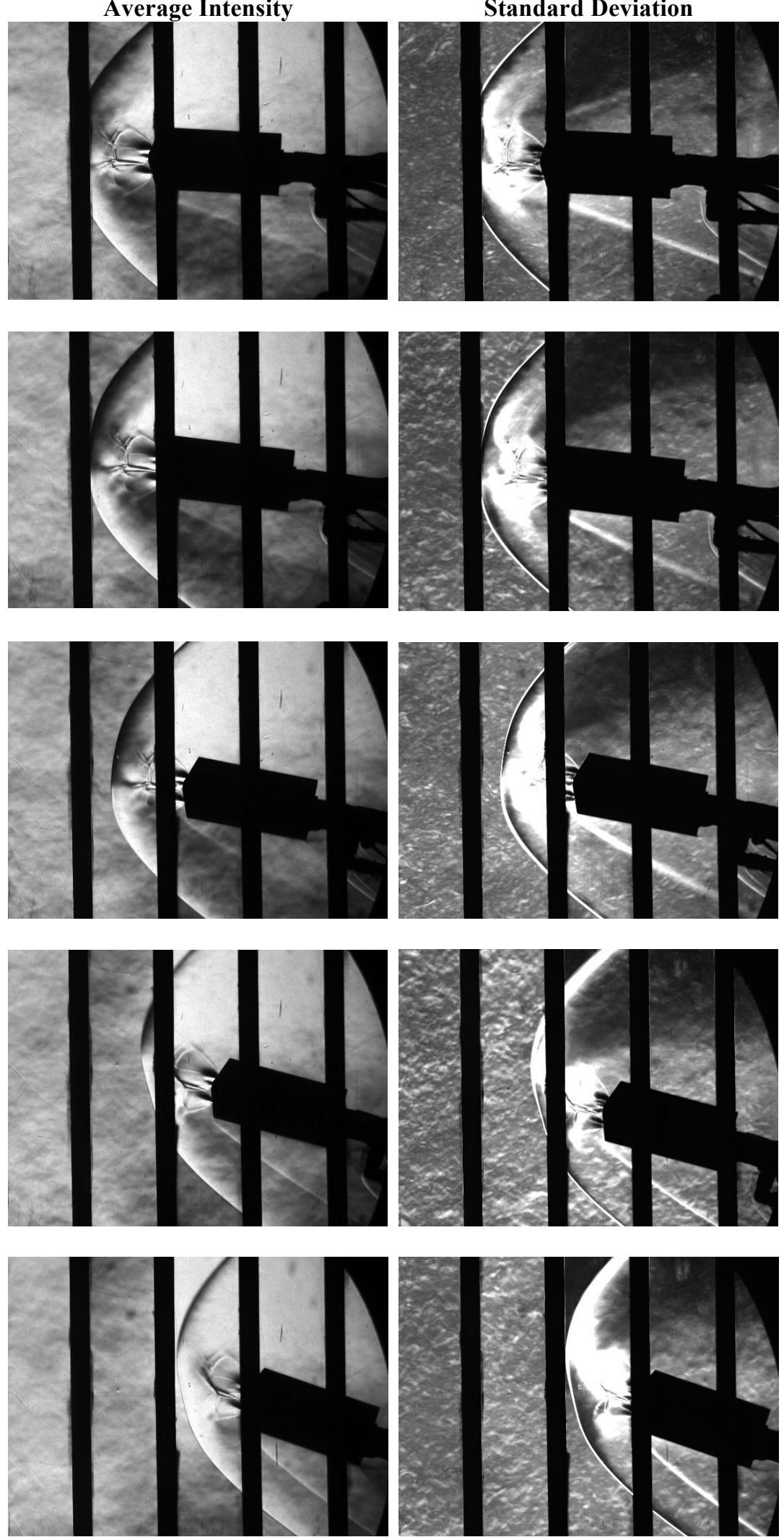

Standard Deviation 


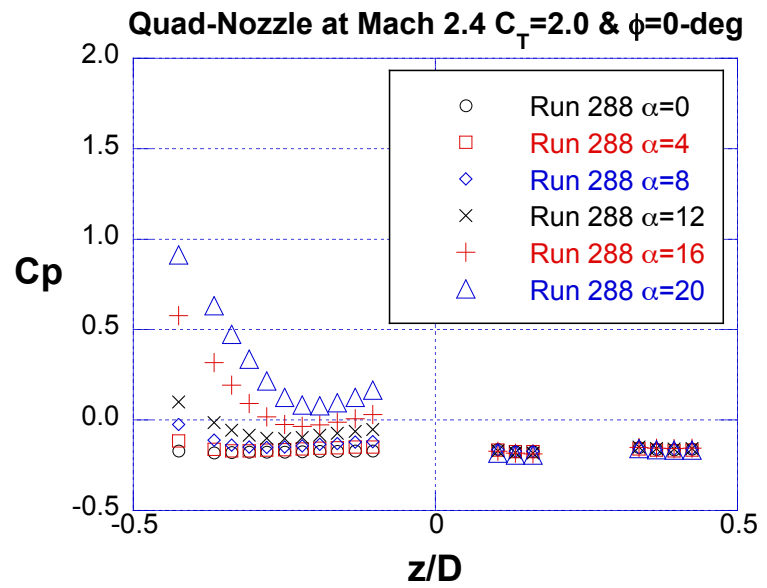

Figure 23 - Plot of the quad pressure data showing the effect of $\alpha$ for $M_{\infty}=2.4, C_{T}=2.0$, and $\phi=0$-deg

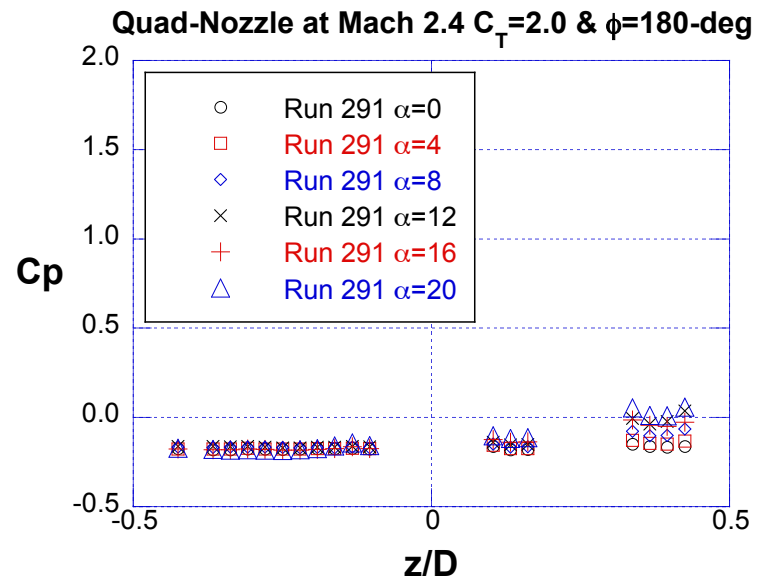

Figure 24 - Plot of the quad pressure data showing the effect of $\alpha$ for $M_{\infty}=2.4, C_{T}=2.0$, and $\phi=180-\mathrm{deg}$

same side that shows a prominent unsteady embedded shock (the angled white line in the standard deviation images) emanating from behind the interaction region.

The effect of angle of attack on $\mathrm{C}_{\mathrm{P}}$ for the quad-nozzle configuration at $\mathrm{M}_{\infty}=2.4, \alpha=0$-deg, and $\mathrm{C}_{\mathrm{T}}=2.0$ are shown in Figs. 23 and 24 for $\phi=0$ and 180 -deg, respectively. It is interesting to note that the unsteady case (Run 288) has higher surface pressures on the windward side of the two cases shown, which is in the region between nozzles. For the steady case (Run 291), the windward ray pressures are low due to local separations near the nozzle. In both cases, the leeward ray appears highly separated.

\section{E. Future Plans}

Continued analysis of this unique and comprehensive dataset is progressing at a systematic pace. Uncertainty analysis is a high priority and requires detailed data review to define specific cases within the dataset for comparison. Thus far, approximately 600 run-pair combinations, many with a significant number of port-to-port pairs, have been identified for comparison and the statistical analysis of these data points is ongoing. The intent is to publish these results separately at a later AIAA conference. In addition, the entire high frequency dataset needs to be processed to identify peak frequencies of interest within the data. Another analysis that could be attempted is to integrate surface pressures to derive approximate aerodynamic data. This analysis is not straight forward, as broad assumptions must be made about surface area assignments for each pressure tap, and since the instrumentation layout is not symmetrical about the model, such analysis could result in substantial uncertainties. Finally, all results are to be compiled in a future NASA test report.

Later this summer, this model will be tested in the Ames 9x7 Supersonic Wind Tunnel at Mach numbers of 1.8 and 2.4. The higher Mach number provides overlap with current results, thus tunnel to tunnel comparisons will be possible, in addition to a limited set of flowfield uncertainty comparisons. In both cases, the intent is for these data to be used to validate SRP computational modeling techniques.

\section{Summary}

An exploratory SRP test has been completed in the Langley Unitary Plan Wind Tunnel Test Section 2 at Mach numbers of 2.4, 3.5, and 4.6. The SRP model consisted of a 5-in diameter 70-deg sphere-cone forebody followed by a roughly 10-in long aftbody. The forebody was designed to allow placement of up to four 4:1 area ratio nozzles. The primary data from this study were surface pressure measurements, though high-speed Schlieren video was also acquired. The intent of this test was to generate validation quality data for comparison against CFD modeling techniques. As such, the run matrix for this study was carefully crafted to allow for quantification of various sources of experimental uncertainty. Preliminary observations of the trends obtained during the test have been provided, mainly intended to show the spectrum of results relevant to future CFD validation efforts. 


\section{Acknowledgments}

The authors would like to acknowledge the support of NASA's Exploration Technology Development and Demonstration (ETDD) Program and Fundamental Aeronautics Program (FAP). The work documented herein was performed jointly by both ETDD's Entry, Descent, and Landing (EDL) Technology Development Project and FAP's Hypersonics Project, both managed at NASA-Langley Research Center. Furthermore, the following individuals were instrumental to this experimental effort: Chris Laws, Courtney Spells, Andrew McCrea, Bil Kleb, Guy Schauerhamer, Kerry Trumble, Bill Oberkampf, Ashley Korzun, Aaron Fuchs, Bryan Falman, Ricky Hall, Paul Bagby, and Steve Jones.

\section{References}

1 Braun, R. D., and Manning, R. M., "Mars Exploration Entry, Descent, and Landing Challenges," Journal of Spacecraft and Rockets, Vol. 44, No. 2, 2007, pp. 310-323.

2 Steinfeldt, B. A., Theisinger, J. E., Korzun, A. M., Clark, I. G., Grant, M. J., and Braun, R. D., "High Mass Mars Entry, Descent, and Landing Architecture Assessment," AIAA Paper 2009-6684, Sept. 2009.

3 Zang, T. A., and Munk, M. M., et al., "Entry, Descent and Landing Systems Analysis Study: Phase 1 Report," NASA TM 2010-216720, July 2010.

4 Edquist, K. T., Dyakonov, A. A., Korzun, A. M., Shidner, J. D., Studak, J. W., Tigges, M. A., Kipp, D. M., Prakash, R., Trumble, K. A., Dupzyk, I. C., "Development of Supersonic Retro-Propulsion for Future Mars Entry, Descent, and Landing Systems," AIAA Paper 2010-5046, June 2010.

5 Korzun, A. M., and Braun, R. D., "Performance Characterization of Supersonic Retropropulsion for High-Mass Mars Entry Systems," Journal of Spacecraft and Rockets, Vol. 47, No. 5, pp. 836-848, 2010

6 Korzun, A. M., Braun, R. D., and Cruz, J. R., "Survey of Supersonic Retropropulsion Technology for Mars Entry, Descent, and Landing," Journal of Spacecraft and Rockets, Vol. 46, No. 5, 2009, pp. 929-937.

7 Jarvinen, P. O., and Adams, R. H., "The Aerodynamic Characteristics of Large Angled Cones with Retrorockets," NASA CR NAS 7-576, Feb. 1970.

8 Trumble, K. A., Schauerhamer, D. G., Kleb, W. L., Carlson, J-R., Buning, P. G., Edquist, K. T., and Barnhardt, M. D., “An Initial Assessment of Navier-Stokes Codes Applied to Supersonic Retro-Propulsion," AIAA Paper 2010-5047, June 2010.

9 Aeschliman, D. P. and Oberkampf, W. L., "Experimental Methodology for Computational Fluid Dynamics Code Validation,” AIAA Journal, Vol. 36, No. 5, May 1988, pp. 733-741.

10 Berry, S.A., Laws, C.T., Kleb, W.L., Rhode, M.N., Spells, C., Mccrea, A.C., Trumble, K.A., Schauerhamer, D.G., Oberkampf, W.L., "Supersonic Retro-Propulsion Experimental Design for Computational Fluid Dynamics Model Validation," IEEE Aerospace Conference Paper No.1499, March 2011.

11 Kleb, W., Carlson, J.R., Buning, P.G., Edquist, K.T., Schauerhamer, D.G., Trumble, K.A., and Sozer, E., "Toward Supersonic Retropropulsion CFD Validation,” AIAA Paper 2011-XXXX, June 2011.

12 Korzun, A. M., Clark, I. G., and Braun, R. D., "Application of a Reynolds-Averaged Navier-Stokes Approach to Supersonic Retropropulsion Flowfields,” AIAA Paper 2011-XXXX, June 2011.

13 Bakhtian, N. M., and Aftosmis, M. J., "Analysis of Inviscid Simulations for the Study of Supersonic Retropropulsion," AIAA Paper 2011-XXXX, June 2011.

14 Jackson, C. M., Jr., Corlett, W. A., and Monta, W. J., "Description and Calibration of the Langley Unitary Plan Wind Tunnel," NASA TP 1905, Nov. 1981.

15 Wassum, D. L. and Hyman, C. E. Jr., "Procedures and Requirements for Testing in the Langley Research Center Unitary Plan Wind Tunnel," NASA TM 100529, Feb. 1988

16 Hollis, B.R., "Real-Gas Flow Properties for NASA Langley Research Center Aerothermodynamic Facilities Complex Wind Tunnels," NASA CR-4755, 1996.

17 Rasband, W.S., ImageJ, U. S. National Institutes of Health, Bethesda, Maryland, USA, http://imagej.nih.gov/ij/, 19972011.

$18 \mathrm{http}: / / \mathrm{www} . v i g y a n . c o m / \mathrm{desl}$

$19 \mathrm{http}: / /$ www.mathworks.com/help/techdoc/rn/rn_intro.html 